\title{
Bilateral homonymous visual field defects as initial manifestation of multiple sclerosis
}

\author{
Bernardo Sanchez-Dalmau, Francisco J Goñi, Mercè Guarro, Carles Roig, \\ Francesc Duch-Bordas
}

\begin{abstract}
Symptomatic suprageniculate lesions in multiple sclerosis expressed as a visual field defect are infrequent. The present case developed a bilateral homonymous defect as the initial and unique symptom of the disease. It was confirmed by nuclear magnetic resonance imaging, which disclosed extensive demyelinating areas in both optic nerve radiations. The mode of onset, perimetric findings, and unusual presentation of this condition are briefly discussed.
\end{abstract}

Symptomatic retrochiasmal disease of the visual pathways in multiple sclerosis (MS) is unusual. An incidence of $1 \cdot 3-3.5 \%$ of homonymous defects has been reported in several series. ${ }^{1-4}$ However, much higher frequencies of retrochiasmal lesions have been found in neuroradiological examinations $s^{5}$ and necropsies ${ }^{6-8}$ without associated clinical manifestations. To our knowledge only one case of clinical simultaneous bilateral retrochiasmal involvement, expressed as a bilateral homonymous hemianopic defect, has been reported. ${ }^{3}$ This case was not studied by CT or nuclear magnetic resonance imaging (NMR).

We report a case that developed a symptomatic simultaneous bilateral homonymous defect as the initial and unique manifestation, examined by CT, NMR, and computerised static perimetry.

\section{Case report}

A 24-year-old woman was admitted to our hospital in July 1989. A fortnight before that she had been seen because of blurred vision. Her visual acuity was $1.0(6 / 6)$ in each eye. The pupillary reactions, ocular motility, and findings on funduscopic examination were all normal in both eyes. Systemic and neurological examinations also gave normal results. Screening computerised perimetry (Short test program, Octopus 500 EZ) showed a congruous left superior quadrantanopic defect and a less delimited depression in the right inferior quadrants, deeper for the left eye. A week later she experienced paraesthesiae in her right upper limb.

On admission to hospital the neurological examination showed isocoria, slightly decreased pupillary reactions without evidence of afferent pupillary defect, and a symmetrical horizontal gaze nystagmus. Funduscopic examination was normal in both eyes. No other neurological symptoms were found. Screening perimetry disclosed a similar visual field loss pattern to that seen on the first occasion (Fig 1). The results of biochemical, haematological, inmunological, and serological blood tests were all normal. A lumbar puncture yielded clear colourless cerebrospinal fluid (CSF). The fluid contained neither red nor white cells; glucose and protein values were within the normal range; immunoglobulin levels were normal, but an IgG $\lambda$ homogeneous component was detected. Microbiological and serological studies of the CSF gave negative results. A chest $x$ ray was normal.

A CT scan of the brain performed without contrast material revealed hypodense, poorly defined lesions. The NMR disclosed extensive
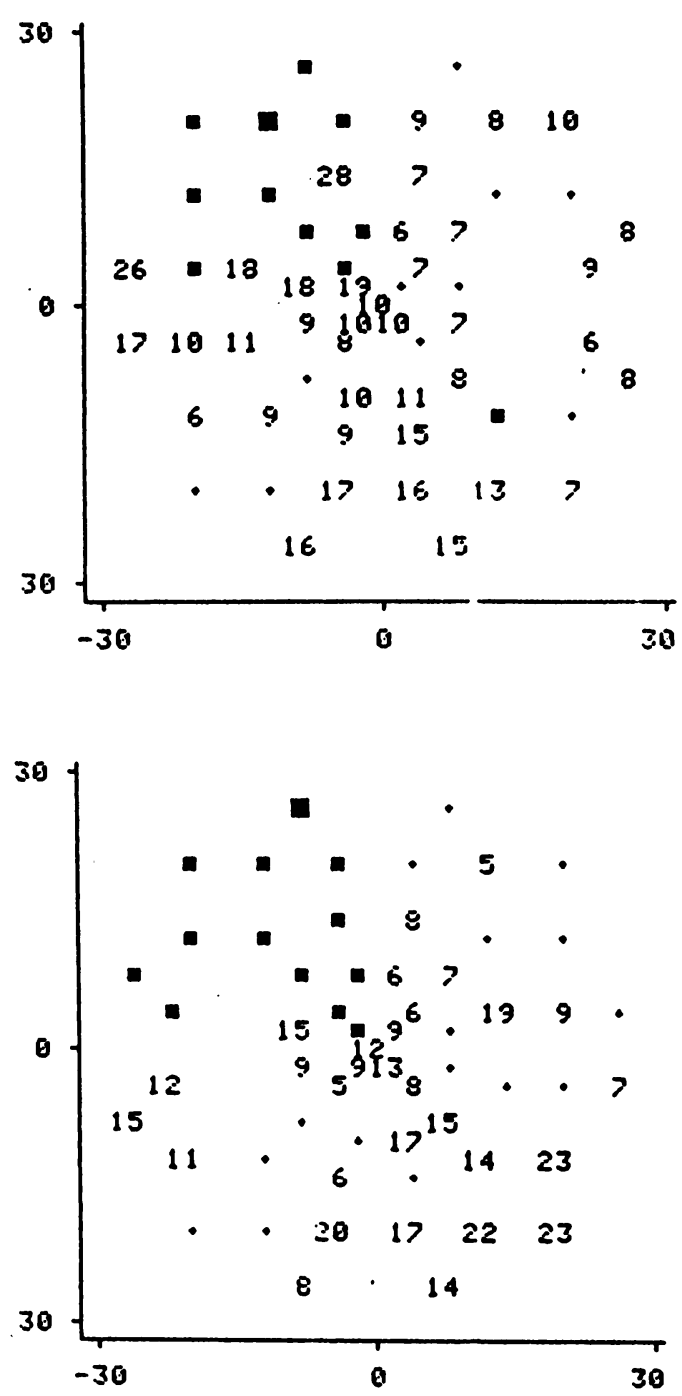

Figure 1 Computerised static perimetry (Short test program, Octopus 500 EZ) of right eye (top) and left eye (bottom), showing congruous left superior quadrantanopic defects and less delimited decreased thresholds in the right inferior quadrants. The remaining quadrants are only relatively spared, expressing deep disease of the suprageniculate visual pathways. 
Figures 2 A, B Axial T2weighted magnetic resonance imaging of the optic

radiations at different levels showing left and right extensive plaques on initial examination on fuly 1989.
Figure 3 A six months computerised perimetry $(G 1$ program, Octopus 500 EZ) of right eye (top) and left eye (bottom), showing significant improvement of thresholds in both eyes, on the table of difference values. The grey-scale tables still depict localised scotomas on the border of the central fields.
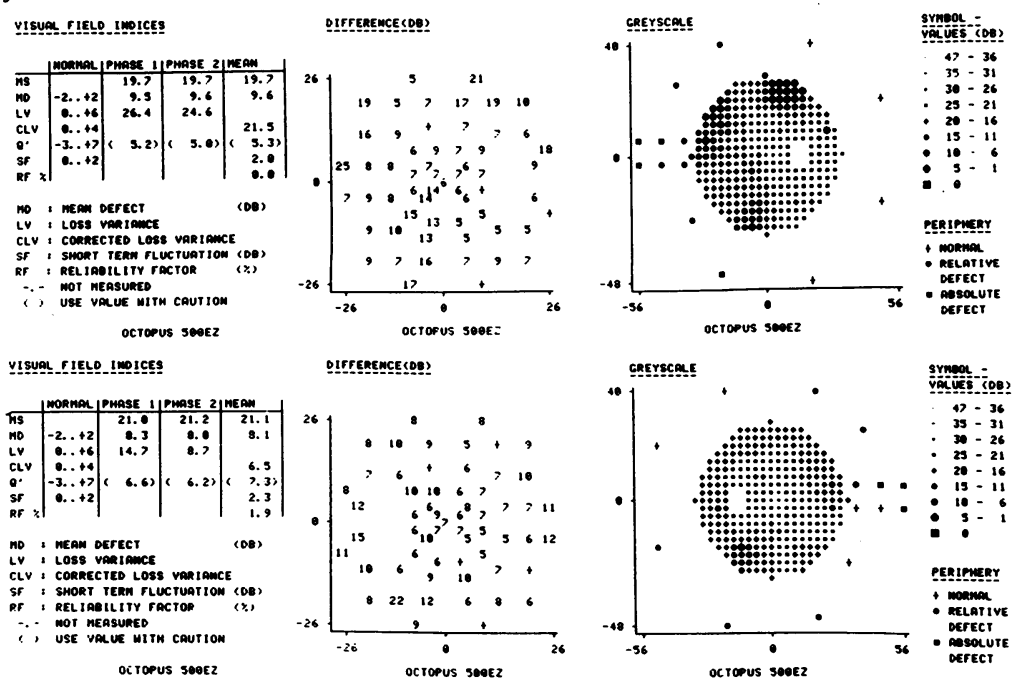
clinical and neurological improvement. The three months, when she was seen in the clinic, a new threshold perimetry performed with the G1 program showed a change of visual field loss pattern. Visual field indices were abnormal and a deep depression still remained. Six months after

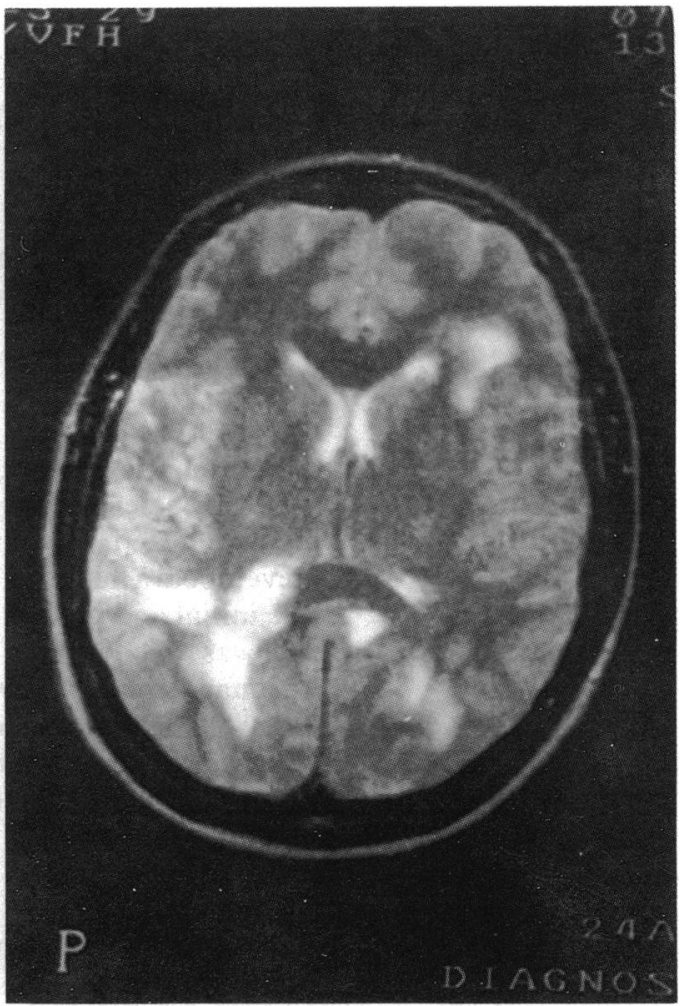

Figure $2 B$

some improvement but still with abnormal indices (Fig 3). At that time another NMR revealed a marked reduction of white matter lesions (Fig 4). major positive wave $(\mathrm{P}-100)$ in both eyes. In hospital the patient had an attack of paresis of the right upper limb with pyramidal symptoms and bilateral impairment of deep sensibility with left predominance, associated with behaviour disorders and psychomotor agitation.

A diagnosis of probable MS according to the classification of McAlpine ${ }^{9}$ was made and treatment with methylprednisolone was started, with patient was discharged a few days later. After admission to hospital another perimetry showed

\section{Discussion}

The onset of MS as homonymous hemianopia due to a suprageniculate lesion of the visual pathways is extremely rare. Beck et $a l^{10}$ reported two cases, one of them without associated neurological symptoms at the onset. Even rarer is the condition of simultaneous bilaterality. Hawkins and Behrens ${ }^{3}$ reported the first case of a simultaneous bilateral homonymous hemianopia but late in the course of the disease. Our patient developed a bilateral visual field defect as the initial and unique manifestation, well characterised by computerised perimetry. It showed a congruous left superior quadrantanopic defect which seemed probably correlated with the right occipital lesion seen in the NMR. The right inferior quadrantanopic depression was less definite, but it was probably produced by a left parieto-occipital plaque. The 10 central degrees of the visual fields were relatively spared (they were mainly seen at the three months perimetry) in accordance with the good visual acuity. In fact suprageniculate lesions produce a deeper defect in the midperiphery than in the central visual field." This case showed a correlation between visual and neuroradiological findings, since improvement on perimetric examination concurred with a marked reduction of plaques in the NMR at the six months appointment.

It is difficult to say why symptomatic suprageniculate lesions are so unusual in MS. The majority of lesions appearing as arcs of temporooccipital white matter are clinically silent, as reported by Jacobs $e t$ al..$^{5}$ On the other hand, many MS patients with no history of visual 
Figures 4 A, B Axial T2weighted magnetic resonance imaging at different levels on the six months examination showing marked reduction of bilateral white matter lesions.

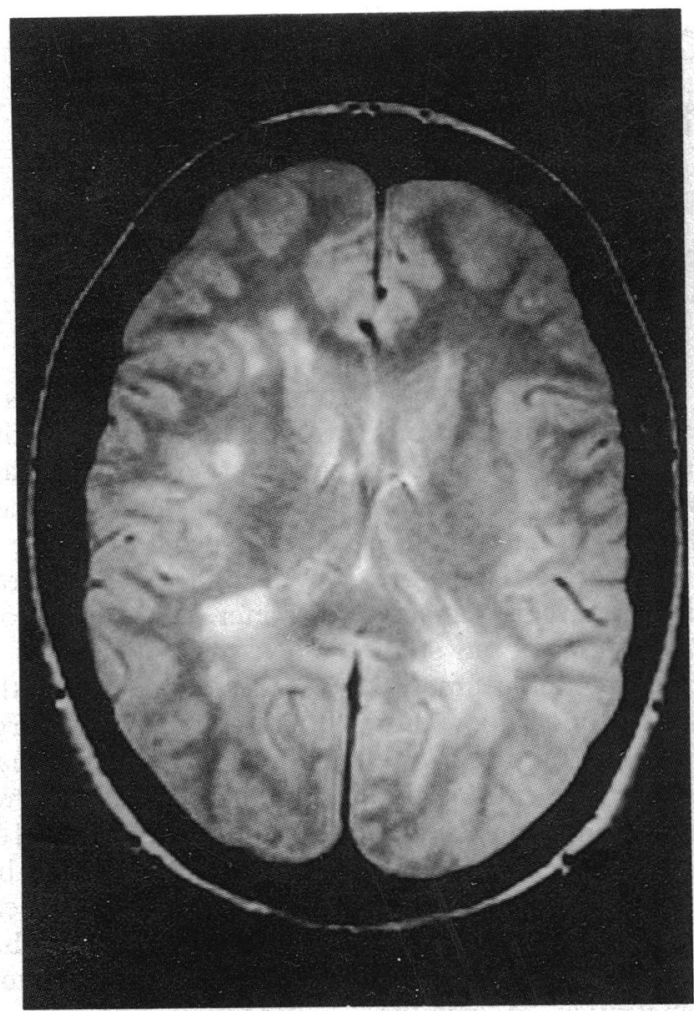

Figure $4 A$

symptoms have abnormal visual fields. ${ }^{12}{ }^{13}$ Most of these abnormalities are probably related to subclinical optic neuritis, but some might be produced by lesions elsewhere than in the optic nerves, including the optic radiations. Thus suprageniculate lesions are likely to be expressed as a subclinical manifestation rather than a symptomatic visual disturbance, as Hawkins and Behrens discussed. ${ }^{3}$ The high sensitivity of threshold static perimetry should be a valuable aid in the better characterisation of these conditions.

1 Kurtzke JF, Beebe GW, Nagler B, et al. Studies on natural history of multiple sclerosis. Acta Neurol Scand 1968; 44: 467-94.

2 Leinfelder PJ. Retrobulbar neuritis in multiple sclerosis. Assoc Res Nerv Dis Proc 1950; 28: 393-9.

3 Hawkins $\mathrm{K}$, Behrens MM. Homonymous hemianopia in multiple sclerosis. Br f Ophthalmol 1975; 59: 334-7.

4 Boldt HA, Haerer AF, Tourtellotte WW, Henderson JW, Dejons RN. Retrochiasmal visual field defects from multiple sclerosis. Arch Neurol 1963; 8: 565-75.

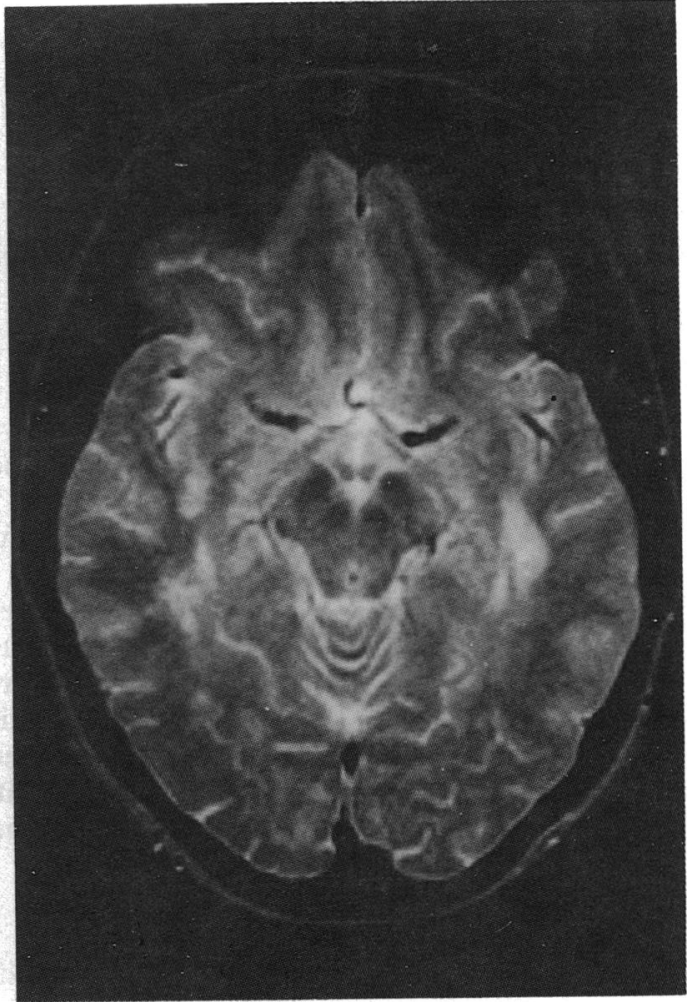

Figure $4 B$

5 Jacobs L, Kinkel WR, Polachini I, Kinkel PR. Correlations of nuclear magnetic resonance imaging, computerized tomography, and clinical profiles in multiple sclerosis. Neurology 1986; 36: 27-34.

6 Savitsky N, Rangell L. The ocular findings in multiple sclerosis. Assoc Res Nero Dis Proc 1950; 28: 403-13.

7 Lehoczky T. Pathologic changes in the optic system in disseminated sclerosis. Acta Morphol Hung 1954; 4: disseminat 408 .

8 Lumsden CE. The neuropathology of multiple sclerosis. In: Vinken PJ, Brnyn GW, eds. Handbook of neurology. Vinken PJ, Brnyn GW, eds. Handbook

9 McAlpine D. In: McAlpine D, Lumsden CE, Acheson ED, eds. Multiple sclerosis: a re-appraisal. Edinburgh: Churchill Livingstone, 1972: 225.

10 Beck RW, Schatz NJ, Savino J. Involvement of the optic chiasm, optic tract and geniculo-calcarine visual system in multiple sclerosis. Bull Soc Belge Ophtalmol 1983; 208 : 159-91.

11 Bynke H. A study of the depth of hemianopic field defects for optimizing computerized perimetry. Neuro-ophthalmology $1984 ; 4: 237-47$.

12 Patterson VH, Heron JR. Visual field abnormalities in multiple sclerosis. F Neurol Neurosurg Psychiatry 1980; 43: 205-8.

13 Grochowicki M, Vighetto A. Etude du champ visuel per l'analyseur de Friedman Mark I et de la vision des couleurs chez 85 patients atteints de sclérose en plaques (SEP). Corrélations avec les PEV dans 50 cas. $\mathcal{F}$ Fr Ophthalmol 1988; 11: 1:61-5. 